\title{
PI and LQR controllers for Frequency Regulation including Wind Generation
}

\author{
Semaria Ruiz ${ }^{1}$, Julian Patiño ${ }^{2,3}$, and Jairo Espinosa ${ }^{1}$ \\ ${ }^{1}$ Departmento de Ingeniería Eléctrica y Automática, Facultad de Minas, Universidad Nacional de Colombia, Medellín, \\ Colombia \\ ${ }^{2}$ Departmento de Ingeniería Eléctrica, Facultad de Ingeniería y Arquitectura, Universidad Nacional de Colombia, \\ Manizales, Colombia \\ ${ }^{3}$ Institución Universitaria Pascual Bravo, Medellín, Colombia
}

\section{Article Info}

Article history:

Received February 21, 2018

Revised May 26, 2018

Accepted June 21, 2018

\section{Keyword:}

Wind Turbines

Load Frequency Control

Linear Quadratic Regulator

Proportional Integral control

Power Systems

\begin{abstract}
The increasing use of renewable technologies such as wind turbines in power systems may require the contribution of these new sources into grid ancillary services, such as Load Frequency Control. Hence, this work dealt with the performance comparison of two traditional control structures, PI and LQR, for secondary regulation of Load Frequency Control with the participation of variable-speed wind turbines. For this purpose, the doubly-fed induction generator wind turbine was modeled with additional control loops for emulation of the inertial response of conventional machines for frequency regulation tasks. Performance of proposed strategies was verified through simulation in a benchmark adapted from the WSCC 3 machines 9-bus test system. Results showed overall superior performance for $\mathrm{LQR}$ controller, although requiring more strenuous control effort from conventional units than PI control.
\end{abstract}

Copyright (C) 2018 Institute of Advanced Engineering and Science. All rights reserved.

\section{Corresponding Author:}

Semaria Ruiz

Departmento de Ingeniería Eléctrica y Automática, Facultad de Minas, Universidad Nacional de Colombia, Medellín, Colombia

Carrera 80 No 65-223 Medellín, Colombia

+5744255092

seruizal@unal.edu.co

\section{INTRODUCTION}

Electricity production from renewable energy sources (RES) has been continually growing. This development is taking place in a power system structure designed for conventional power sources, with characteristics such as availability, controllability, and reliability utterly different to those of RES systems [1][2]. Also, the energetic production of RES may fluctuate significantly over time due to some characteristics of natural resources, such as unpredictability, variability, and dependency on the geographic location [3] [4]. In particular, some issues attracting a lot of interest in the technical community are the active power variations and frequency performance in presence of RES [1][3] [5], for systems including solar photovoltaic (PV) panels [6] and mostly for wind turbines (WT) [7].

In power systems, frequency constitutes a parameter indicating the equilibrium between power demanded by load and the energy produced by generation systems [8]. When this relationship is unbalanced, control structures are in place to return system frequency to the right operational values. However, these frequency control strategies have been developed for a power system with almost complete reliance on conventional energy sources, and the penetration of RES may require the participation of these new units in the control tasks [3]. Wind turbines, particularly those of variable-speed with doubly-fed induction (DFIG), constitute one of the most used RES around the world [9] [10]. Hence, several studies have been proposed about control strategies for the active inclusion of DFIG WT in Load Frequency Control loops, and complete reviews can be found in references [7] [11] [12]. 


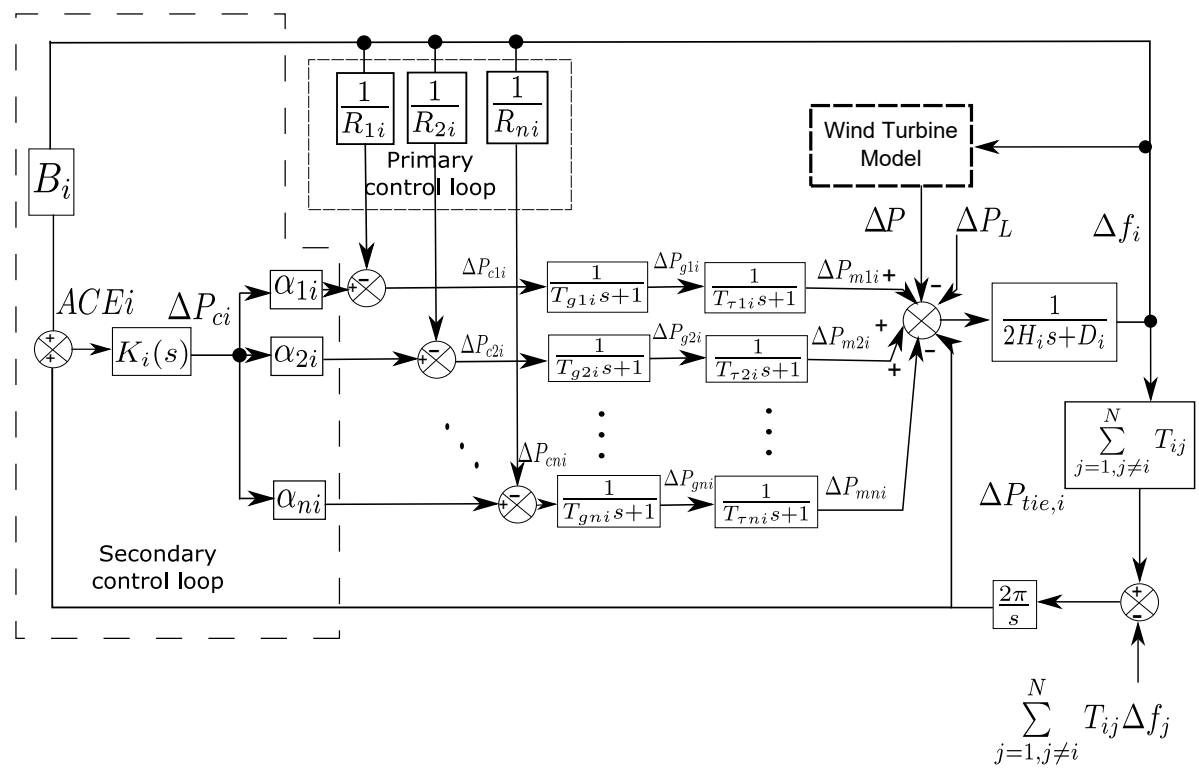

Figure 1. LFC scheme for a multi-area ( $N$ areas) power system, including primary and secondary control loops [1]. The block "Wind Turbine Model" integrates WT to LFC.

One of the most used strategies for DFIG contribution in frequency regulation, is the so-called synthetic inertia method, as explained in the studies [13] and [14]. In this technique, additional control loops are developed for the WT with the goal of emulating frequency response of conventional generators. This alternative was explored in other works where controllers based on the dynamic representations of the DFIG WT were proposed. In [15] a Linear Quadratic Regulator type of controller is designed for the WT, taking as model inputs the reference torque and the reference pitch angle of the turbine. The work of Mohamed et al. [16] proposes a Model Predictive Controller for WT integration to frequency regulation, using a simplified model of the DFIG with the quadrature-axis rotor voltage as the model input. However, these studies are not exploring WT penetration in a multi-area scenario for power systems, an increasingly common operational possibility as grid grows in size and RES integration level arises. Also, a performance comparison of some of the proposed strategies over the same scenario would be useful to establish the most suitable control structure for WT contribution in frequency regulation tasks. This paper addresses both of the formerly mentioned issues, comparing the performance of PI-based and LQR-based controllers for DFIG WT integration into Load Frequency Regulation (LFC) structure for a multi-area power system. The simulation is performed in a modified version of the 9-bus WSCC power system [8].

This work is the continuation of the research with preliminary results reported in [17]. The former paper focused on the utilization of the synthetic inertia model for WT integration into LFC of power systems with PI controllers. Our current article presents a more elaborated description of the non-linear state-space realization employed for the modeling of variable speed wind turbines. Moreover, DFIG wind turbine operation includes a pitch-angle control loop. Also, additional control structures are explored with the consideration of LQR controllers for secondary regulation, and a performance comparison discussion versus PI strategies. Current paper is divided as follows: Section 2. describes the LFC structure for power systems. Section 3. deals with the WT modeling and the formulation of PI and LQR controllers. Simulation tests and performance comparisons appear in Section 4.. At last, some conclusions are presented in Section 5.

\section{LOAD FREQUENCY CONTROL IN MULTI-AREA POWER SYSTEMS}

Frequency regulation can be classified in three main stages according to the nature and timing of the control efforts: primary actions proportional to the frequency deviations, secondary actions allowing correction of steady-state errors, and tertiary actions related with predefined dispatches and some emergency conditions. These three stages constitute the Load Frequency Control (LFC) system [8, 1].

Grid elements must be modeled for the design of LFC controllers. First order models are assumed for the governor and turbine of conventional units, and for the representation of the frequency response char- 


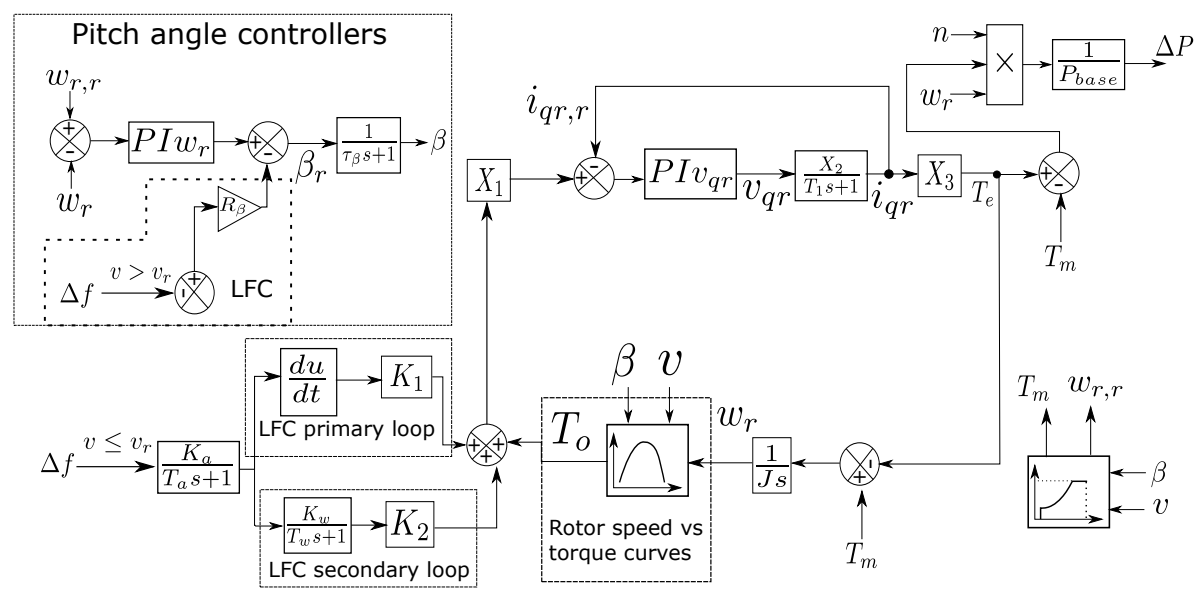

Figure 2. Wind turbine model with frequency response and variable wind speed (based on [19]).

acteristic of any control area in the power system. Figure 1 shows the LFC for a $N$-area power system, where parameters for the $i$-th area are: $\Delta P_{m k i}$ the change in mechanical power of the generator $k, \Delta P_{g k i}$ the change in the active power output of generator $k, \Delta P_{L}$ the load perturbation, $\Delta f_{i}$ the frequency change, $D_{i}$ the damping coefficient. $H_{i}$ the equivalent inertia, $\Delta P_{c k i}$ the control action of the LFC for the $k$-th generator, $T_{i j}$ the power exchange coefficient between area $i$ and area $j, \Delta P_{t i e i}$ the total change in the power exchanged between area $i$ and other areas and $\Delta f_{j}$ the change in the frequency of area $j$ connected to area $i$. Also, $B_{i}$ denotes the bias factor for modulation of the error signal in secondary regulation, $K_{i}(s)$ is the transfer function of the secondary controller and $\alpha_{i}$ the participation factor of each generator in secondary control.

\section{INCLUSION OF VARIABLE SPEED WT IN LFC}

This work only considered variable-speed DFIG WT, as they are the best-suited WT for active participation in grid ancillary services [18]. However, WT units with DFIG do not present a natural inertial response to frequency changes [1]. For enabling frequency response capabilities to the DFIG WT, synthetic inertia control strategy [14] was employed. This technique proposes operation of the DFIG WT below the point of maximum power extraction to maintain a reserve of kinetic energy to be used for frequency compensation. The operating point $P_{o}$ depends on the DFIG angular speed $w_{r}$ and the so-called operational torque $T_{o}[N \mathrm{~m}]$, calculated as indicated in equation 1 for different values of wind speed $v$. Gain $K_{o p}$ is adjusted for the operation of the WT under the curve formed by the points of maximum withdrawable power from wind at each speed.

$$
T_{o p}=K_{o p} v^{2} .
$$

For the electromagnetic component of the DFIG, the simplified model proposed in [13] [19] is used and included in the LFC as the wind-turbine model block in Figure 1. This representation, denominated as synthetic-inertia model, is a reduced induction-machine model of fourth order and only uses the quantities in $q$-axis, as the $d$-axis is selected as the reference frame. Figure 2 presents both models.

In the scheme of Figure 2, $P_{b a s e}$ is the nominal power of the area, $w_{r}$ is the angular speed of rotor, $n$ is the quantity of WTs, $v_{q r}$ is the rotor quadrature voltage, $i_{q r}$ is the rotor quadrature current, $i q_{r, r}$ is the reference quadrature current for rotor, $P I v_{q r}$ is the PI controller for $v_{q r}, T_{e}$ is the electromagnetic torque, $T_{m}$ is the mechanical torque, $\beta$ is the blade pitch angle, $\beta_{r}$ is the blade pitch angle reference, $\tau_{\beta}$ denotes the time delay of pitch angle actuator, $w_{r, r}$ is the rotor angular speed reference, $P I v_{q r}$ is the PI controller for $w_{r}, v_{r}$ is the rated wind speed of WT, $K_{1}$ is the proportional action of primary control, $K_{2}$ is the proportional action of secondary control, $K_{w}$ and $T_{w}$ are the gain and time delay of secondary control loop, $J$ is the inertia moment of WT, and $X_{1} X_{2}, X_{3}$, and $T_{1}$ are approximately constant values representing some combinations among DFIG internal generator parameters (see [13] and [20] for detailed explanation).

As seen from Figure 2, several control loops are added to the simplified turbine model to emulate the behavior of the different control stages of the LFC structure and to keep the stable operation of the DFIG WT after contribution to frequency regulation. These loops are described as follows:

1. A primary response loop for the DFIG labeled as $L F C$ primary loop in Figure 2. Proportional gain $K_{1}$ is 
modulating the frequency change rate $\frac{d \omega}{d t}$.

2. A secondary response loop marked as LFC secondary loop in Figure 2 operating in the same way as the secondary control of LFC. The power delivered by WT is restored to the nominal operating point after a control of frequency disturbances.

3. The pitch-angle controller loop in Figure 2, tasked with maintaining the angular speed of the WT at nominal operating value for wind speeds equal or over the rated ones. Under the action of pitch control, in case of a frequency disturbance occurring, an additional control loop is required for modulating pitch angle with a gain $R_{\beta}$ proportional to frequency deviation.

The area deviation frequency signal is filtered (through a filter with gain $K_{a}$ and time delay $T_{a}$, see Figure 2) before being applied to primary and secondary control loops. This work performs a comparison of the mentioned loops for two different secondary controllers in frequency regulation. The following subsections describe the PI and LQR secondary controllers (see $K_{i}(s)$ block in Figure 1) and their interaction with the WT control scheme.

\subsection{Considerations for system with secondary PI controller}

Proportional Integral (PI) control constitutes the most used variation of the Proportional Integral Derivative (PID) structure [21]. Starting from a simple Single-Input Single-Output (SISO) loop [21], the transfer function $C_{P I}(s)$ of the PI controller is $C_{P I}(s)=K_{p}\left(1+\left(T_{r} s\right)^{(}-1\right)$. The term $K_{p}$ is the Proportional gain, $T_{r}$ is known as the reset time [21], and the relationship $\left.K_{p}\left(T_{r}\right)^{(}-1\right)$ is called the integral gain.

PI controllers constitute the traditional strategy for secondary regulation in LFC system. In this work, additional PI controllers regulate quadrature rotor current $\left(P I i_{q r}\right)$ and the pitch angle $\left(P I w_{r}\right)$, as shown in Figure 2.

\subsection{Considerations for LFC system with secondary LQR controller}

Criterion-based synthesis of controllers is a design technique driven by the complexity of multivariable systems. A commonly employed set of criteria is formed by cost functions related to quadratic forms of control effort and error signals [21]. For linear case, the so-called Linear Quadratic Regulator expresses the problem as the feasible solving of the dynamic Riccati equation in continuous time, leading to a time-variable state feedback [21].

For this configuration, secondary controller $K_{i}(s)$ requires a state-space representation of the whole LFC. Equations (2) to (11) describe the complete non-linear state-space model for a multi-area power system with integration of WT to the LFC scheme, adapted from [16]. This representation includes the transferred power between areas $\Delta P_{t i e}$ as a state, with an additional state equation for WT pitch-angle $\beta$ (see eq. (8)) as a parameter with high influence in the contribution of WT to LFC [15].

$$
\begin{gathered}
\dot{\Delta f=} \frac{\Delta P_{m}-D \Delta f-\Delta P_{L}}{2 H}-\frac{\Delta P_{\text {tie }}}{2 \pi} \\
+\left(\frac{X_{3} w_{r} i q_{r} n-P_{r e f}}{P_{\text {base }}}\right) \frac{\Delta f}{2 H} \\
\Delta \dot{P}_{t i e}=2 \pi \sum_{j=1}^{N} T_{i, j} \Delta f+\frac{\Delta P_{c}}{T_{g}}-2 \pi v_{i} \\
\Delta \dot{P}_{m}=\frac{-\Delta P_{m}}{T_{\tau}}-\frac{\Delta P_{g}}{T_{g}} \\
\Delta \dot{P}_{g}=\frac{-\Delta f}{R T_{g}}-\frac{\Delta P_{g}}{T_{g}}+\frac{\Delta P_{c}}{T_{g}} \\
\dot{i_{q r}}=\frac{-i_{q r}}{T_{1}}+\frac{v_{q r}}{T_{1}} \\
\dot{w}_{r}=\frac{-X_{3} i_{q r}}{J}+\frac{T_{m}}{J}
\end{gathered}
$$




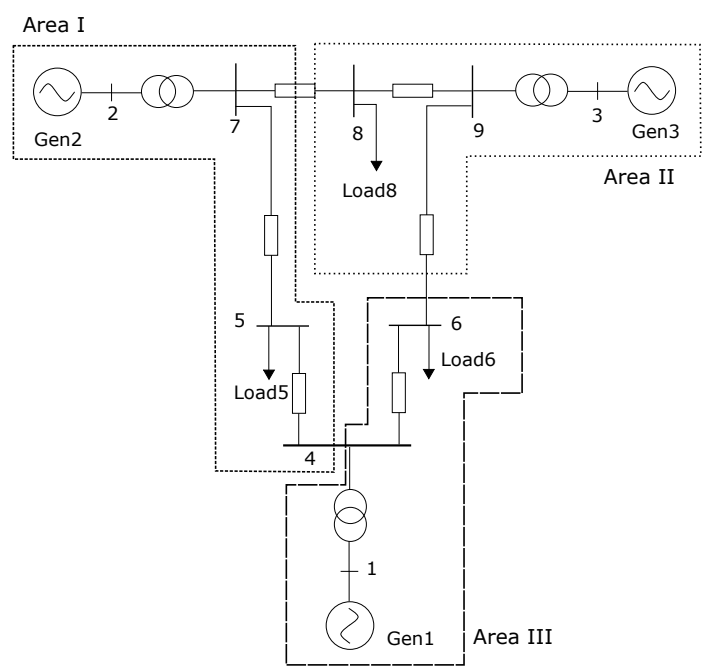

Figure 3. WSCC 9-bus system multi-area partitioning. System parameters can be found in [8].

$$
\dot{\beta}=\frac{-\beta}{\tau_{\beta}}+\frac{\beta_{r e f}+R_{\beta} \Delta f}{\tau_{\beta}}
$$

Mechanical torque $T_{m}$ is calculated from parameters such as air density, length of turbine blades and WT power coefficient $C_{p}$ (fraction of available wind power being extracted). Differences with [16] involve the consideration of pitch angle reference $\beta_{\text {ref }}$ as an input, and wind speed $v$ and frequency deviation of neighboring areas $\Delta f_{j}$ as outputs. Complete vectors of system inputs $U$ and disturbances $W$ are shown below, with $\Delta P_{L}$ the deviations in demanded-load:

Mechanical torque is calculated dividing equation (9) by the angular rotor speed:

$$
P_{m}=\frac{1}{2} \rho \pi R^{2} v^{3} C_{p}
$$

where $\rho$ represents air density, $R$ is the length of the turbine blades and the power coefficient $C_{p}$ denotes the fraction of available power in the wind that is being harvested. This parameter is a function of the Tip-Speed Ratio (TSR) denoted by $\lambda=\frac{R w_{r}}{v}$, and the collective blade pitch $\beta$.

$$
U^{T}=\left[\begin{array}{lll}
v_{q r} & \Delta P_{c} & \beta_{r e f}
\end{array}\right], W^{T}=\left[\begin{array}{lll}
\Delta P_{L} & \Delta f_{j} & v
\end{array}\right]
$$

Finally, vector $Y$ presents system outputs in equation (11). The first output is the rotor quadrature current $i_{q r}$, whose reference is given by $i_{q r, r}$. The second output is the system Area Control Error (ACE), reference signal for the LFC secondary controller $\left(A C E=\Delta f+\Delta P_{t i e}\right)$. The last output is the rotor angular speed, whose reference is defined for a given mechanical torque.

$$
y^{T}=\left[\begin{array}{lll}
i q_{r} & \beta \Delta f+\Delta P_{t i e} & w_{r}
\end{array}\right] .
$$

\section{RESULTS}

\subsection{Description of case of study}

A slightly modified version of the WSCC 9-bus power system [8] was employed for simulation of the DFIG participation in the LFC for a multi-area power. The modified system parameters are summarized in Table 1. This system was partitioned into three areas, as illustrated in Figure 3. Consider Generator 1 as hydraulic and Generators 2 and 3 as gas units. For the sake of this work, $50 \%$ of conventional generation in Area III was replaced by a wind farm. The wind farm was formed by 32 DFIG WT of $2 M W$ each, whose model parameters are shown in Table 2 . Wind speed was simulated from a normally distributed random signal with a period of 50 seconds, mean value of $12.5 \mathrm{~m} / \mathrm{s}$ and variance of $2.8 \mathrm{~m} / \mathrm{s}$. Finally, load disturbances were applied as follows: an increment of $0.06[p . u]$ at 30 seconds of operation in area III; a variation of magnitude $0.08[p . u]$ at 60 seconds in area II; and another disturbance of $0.01[p . u]$ at 90 seconds for area I. The Power Base is set at $100 M V A$. 
Table 1. WSCC 9 bus system parameters [8].

\begin{tabular}{cc|cc|cc}
\hline Parameter & Value & Parameter & Value & Parameter & Value \\
\hline$H_{1}$ & $23.64 \mathrm{~s}$ & $T_{12}$ & 2.064 p.u. & $R_{1}$ & 2 p.u. \\
$H_{2}$ & $6.4 \mathrm{~s}$ & $T_{13}$ & 6.1191 p.u. & $R_{2}$ & 10 p.u. \\
$H_{3}$ & $1.505 \mathrm{~s}$ & $T_{23}$ & 14.4353 p.u. & $R_{3}$ & 7.5019 p.u. \\
$M V A_{\text {nom } 1}$ & 247.5 & $D 1, D 2, D 3$ & 0.8 & $B_{1}$ & $2.8 \mathrm{~s}$ \\
$M V A_{\text {nom } 2}$ & 192 & $T g 1, T g 2, T g 3$ & 0.2 & $B_{2}$ & $10.8 \mathrm{~s}$ \\
$M V A_{\text {nom } 3}$ & 128 & $T_{\tau 1}, T \tau 2, T \tau 3$ & 0.3 & $B_{3}$ & $8.3 \mathrm{~s}$ \\
\hline
\end{tabular}

Table 2. Wind-turbine model simulation parameters [14].

\begin{tabular}{cc|cc}
\hline Parameter & Value & Parameter & Value \\
\hline$P_{\text {nom }}$ & $2 M W$ & $R_{s}$ & $0.00491 \mathrm{p.u}$. \\
$V_{n o m}$ & $966 \mathrm{~V}$ & $X_{l s}$ & 0.09273 p.u. \\
$K_{1}$ & $5000 \mathrm{Nm}$ & $X_{m}$ & $3.96545 \mathrm{p.u}$. \\
$K_{2}$ & $2000 \mathrm{Nm}$ & $R_{r}$ & $0.00552 \mathrm{p} . \mathrm{u}$ \\
$T_{w}$ & 1 & $X_{l r}$ & $0.1 \mathrm{p.u}$. \\
$K_{a}$ & 500 & $H$ & $4.5 \mathrm{~s}$ \\
$T_{a}$ & 20 & $J$ & $506.6059 \mathrm{Kgm}^{2}$. \\
\hline
\end{tabular}

\subsection{Tuning of PI controllers}

PI controllers for secondary frequency regulation in each area were tuned using the Gradient Descent method, along with $P I$ controllers of rotor angular speed $w_{r}$ and rotor quadrature voltage $v_{q r}$. Table 3 presents the parameters for all of them.

Table 3. Parameter values for the different PI controllers in simulation for the case of study.

\begin{tabular}{ccc}
\hline Controller & Proportional Gain $k_{P}$ & Integral Gain $k_{I}$ \\
\hline PI Area I & 0 & -0.05 \\
PI Area II & 0 & -0.05 \\
PI Area III & 0 & -0.28 \\
PI $v_{q r}$ & 0 & 2.70 \\
PI $w_{r}$ & 7.19 & 0.53 \\
\hline
\end{tabular}

\subsection{Tuning of $L Q R$ controller}

To calculate the gains of LQR controller with reference tracking, a linearization must be performed in the non-linear state-space model described by equations (2) to (8). This process results in the operating point vectors $U_{o p}^{T}=\left[\begin{array}{lll}27.97 & 0.08 & 9\end{array}\right]$ for the inputs and $W_{o p}^{T}=\left[\begin{array}{lll}0.2 & 0 & 12\end{array}\right]$ for disturbance signals. Design of LQR controllers for secondary LFC implies the tuning of the positive definite matrices $Q_{\text {area }}$ and $R_{\text {area }}$ for each area. The adjusted matrix elements are listed in Table 4.

Table 4. Parameter values for the different PI controllers in simulation for the case of study. Matrix dimensions for area III are different due to the presence of wind generation.

\begin{tabular}{cc}
\hline Parameter & Value \\
\hline$Q_{\text {area } 1}$ & $\operatorname{diag}\left(\left[1,1,10^{-1}, 10^{-1}, 10^{3}\right]\right)$ \\
$Q_{\text {area } 2}$ & $\operatorname{diag}\left(\left[1,1,10^{-1}, 10^{-1}, 10^{3}\right]\right)$ \\
$Q_{\text {area } 3}$ & $\operatorname{diag}\left(\left[10^{2}, 10^{2}, 5,5,10^{-2}, 10^{-2}, 10^{-2}, 1,10^{6}, 10^{2}\right]\right)$ \\
$R_{\text {area } 1}$ & $10^{7}$ \\
$R_{\text {area } 2}$ & $10^{2}$ \\
$R_{\text {area } 3}$ & $\operatorname{diag}\left(\left[10^{2}, 10^{6}, 10^{9}\right]\right)$ \\
\hline
\end{tabular}




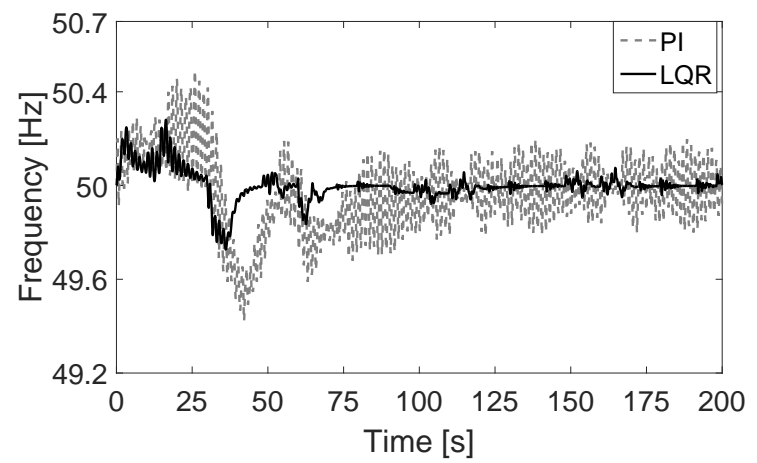

Figure 4. Frequency deviation in area II. LQR achieved a reduction of $0.32 \mathrm{~Hz}$ over PI response in maximum value.

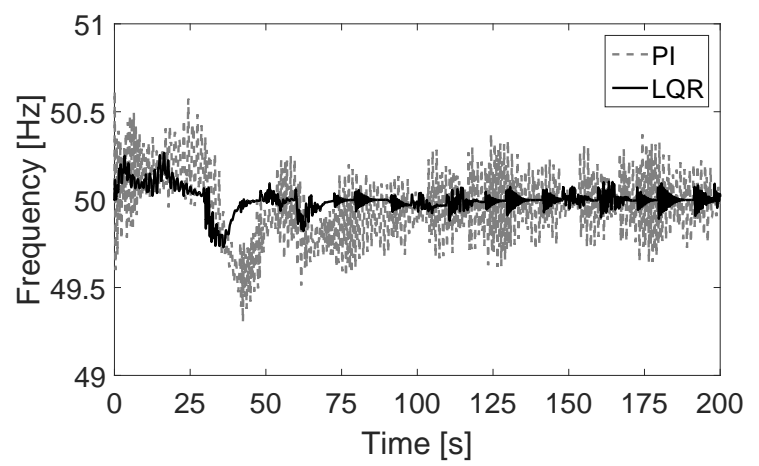

Figure 5. Frequency deviation in area III. Peak deviation value for PI was $0.17 \mathrm{~Hz}$ bigger than LQR.

\subsection{Comparison between PI and LQR controlled LFC with WT participation}

Simulations were performed on the selected benchmark with models and conditions previously described. Figures 4 and 5 depict frequency deviations for areas II and III respectively, as they present more significant variations than area I. Load disturbance in area III at 30 seconds causes the most notorious effects, not only in the local frequency deviation but also in the other areas as well. This behavior could be attributed to the inertia reduction in region 3 and some latency in the operation of WT control loops: power transferred to area III increases as WT contributions in frequency regulation start. On the other hand, the overall magnitude of the frequency deviations over the total simulation time is smaller for the LQR controller in each area. Fewer variations would mean less stress in the regulation systems, a key factor as RES penetration increases. Also, longer recovery and settling times can be seen for PI controllers at each area, giving the LQR a better overall performance for secondary control design in the studied case.

Figure 6 shows the exchanged powers between area III and the other areas. In this case, LQR reduces the power exchanged with other areas when compared with PI response. However, a continued oscillation in power is observed, due to wind variability causing fluctuations in WT generation. This variation makes area III more sensitive to sudden changes in load, as confirmed when the most significant power deviations appear at the same time as the load disturbances occur. With a load disturbance in area III at 30 seconds, LFC system requires an increase in power transference from the other areas to mitigate frequency fluctuations. However, the exchanged power in area III stabilizes as WT start contributing to frequency regulation. Figure 7 shows the power generated by the wind farm in area III.

Focusing on DFIG WT performance, analysis of the control efforts for both LQR and PI strategies in area III is required. Control actions for the pitch-angle $\beta_{\text {ref }}$ are smaller for LQR than for PI controller, as seen in figure 8. This behavior seems to indicate that WT's are less stressed with LQR controller. However, the total control effort of the secondary control $\Delta P_{c}$ is higher for the LQR than the PI scheme, as shown in Figure 9. LQR is imposing an aggressive control action in the conventional unit of area III, diminishing the stress in WT contributions to frequency regulation. This, in turn, reduces frequency fluctuations due to wind variability for 


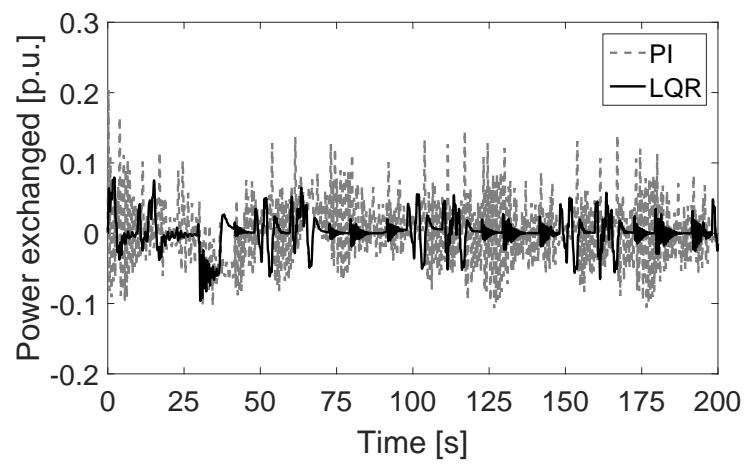

Figure 6. Inter-area power exchange deviation for area III.

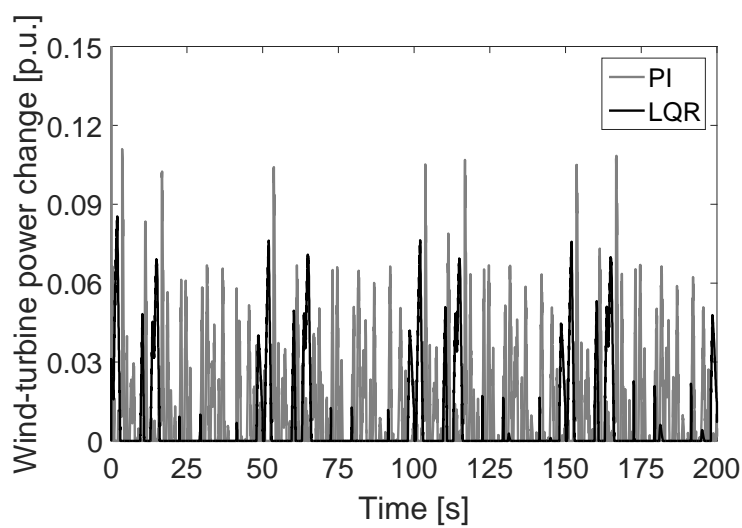

Figure 7. Variations in power generated by the wind farm in area III. 


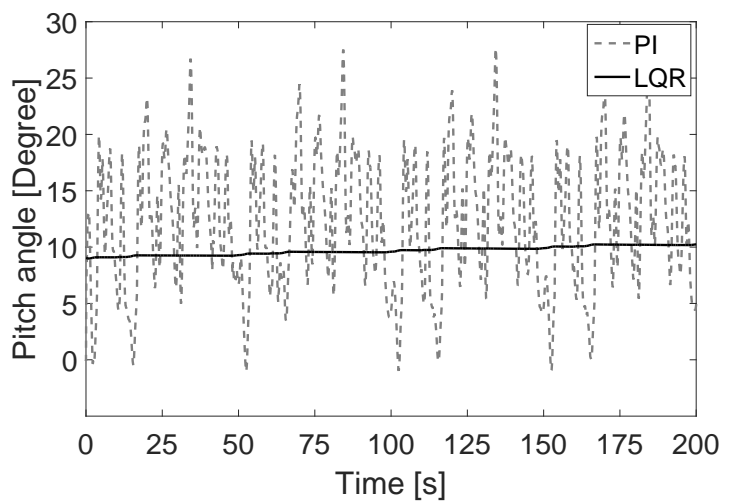

Figure 8. Magnitude of control action for variable $\beta_{\text {ref }}$ in area III

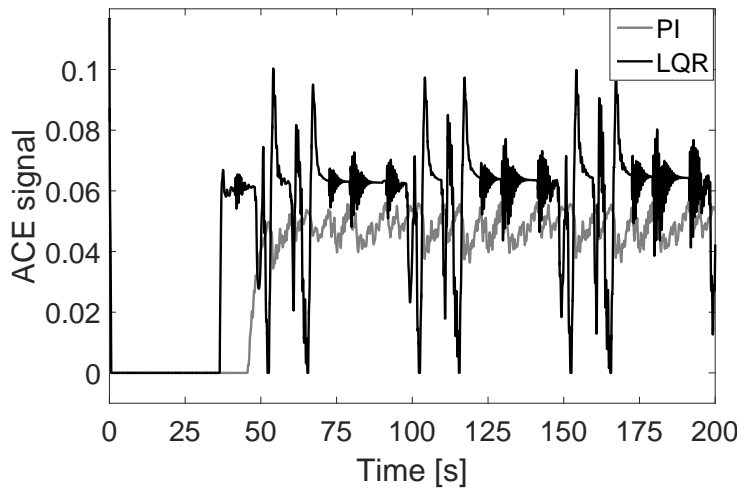

Figure 9. Magnitude of control action for variable $\Delta P_{c}$ in area III.

the LQR in this area.

\section{CONCLUSIONS}

This work studied the performance of variable-speed wind turbines in LFC structure of power systems. With inertial response emulation methodology, DFIG WT were included in the primary regulation stage of the LFC. Two controllers were compared for secondary regulation in the test system, and Linear Quadratic Regulator presented a better overall performance than the Proportional Integral controller. For every explored case, frequency deviations under LQR strategy were smaller and the settling times of the output variables were also lower than the PI-controlled results. Furthermore, LQR operation diminished control efforts of WT. LQR controller based on the system model and it achieved acceptable performances despite the mandatory requirement for linearization of the state-space representation. An unwanted overshoot in area III frequency appears for both strategies with sudden wind variations. This reaction occurs because the operating point of the system is changing with every value of wind speed. This effect was more notorious for LQR configuration, as the model implemented included wind speed as a disturbance. When the operating point changed, linearization might have lead to the inadequate representation of the nonlinear system. Neither PI nor LQR presented a total disturbance rejection, and wind variability may require the pairing of WT with "continuous" generation to reduce operational uncertainty.

Consideration of additional control schemes for the participation of variable-speed WT in LFC enables the contribution of WT to ancillary tasks. However, the increment of WT in power systems may lead to inertia reduction with the decreasing operation of conventional generation systems. More advancements and studies are needed to get a better performance of the wind units in frequency regulation tasks or expanding their role into secondary control. Finally, the implementation of a transition-band control loop between torque and pitch controllers of WT is suggested. This additional loop would help to avoid overshoots in WT generated power when wind varies from nominal speed. 


\section{ACKNOWLEDGEMENT}

Colciencias supported contributions of S. Ruiz and J. Patino through the programs "Jóvenes investigadores - Convocatoria N.645 of 2014" and "Convocatoria 528 - Convocatoria Nacional para Estudios de Doctorados en Colombia 2011", respectively.

\section{REFERENCES}

[1] H. Bevrani, Robust Power System Frequency Control, 2nd ed., ser. Power Electronics and Power Systems. Springer, 2014

[2] E. Duque, J. Patino, and L. Veléz, "Implementation of the ACM0002 methodology in small hydropower plants in Colombia under the Clean Development Mechanism," International Journal of Renewable Energy Research, vol. 6, no. 1, pp. 21-33, 2016. [Online]. Available: www.scopus.com

[3] C. L. DeMarco and C. A. Baone, "Chapter 29 - Control of Power Systems with High Penetration Variable Generation," in Renewable Energy Integration, L. E. Jones, Ed. Boston: Academic Press, 2014, pp. 369 $-379$.

[4] S. Ruiz, J. Patino, A. Marquez, and J. Espinosa, "Optimal Design for an Electrical Hybrid Microgrid in Colombia Under Fuel Price Variation," International Journal of Renewable Energy Research, vol. 7, no. 24, pp. 1535-1545, 2017.

[5] J. Patino, F. Valencia, and J. Espinosa, "Sensitivity analysis for frequency regulation in a two-area power system," International Journal of Renewable Energy Research, vol. 7, no. 2, pp. 700-706, 2017.

[6] C. Rahmann and A. Castillo, "Fast Frequency Response Capability of Photovoltaic Power Plants: The Necessity of New Grid Requirements and Definitions," Energies, vol. 7, no. 10, p. 6306, 2014.

[7] F. Díaz-González, M. Hau, A. Sumper, and O. Gomis-Bellmunt, "Participation of wind power plants in system frequency control: Review of grid code requirements and control methods," Renewable and Sustainable Energy Reviews, vol. 34, pp. 551 - 564, 2014.

[8] P. M. Anderson and A. A. Fouad, Power System Control and Stability (IEEE Press Power Engineering Series). Wiley-IEEE Press, 2002.

[9] A. Boulahia, M. Adel, and B. Hocine, "Predictive Power Control of Grid and Rotor Side converters in Doubly Fed Induction Generators Based Wind Turbine," International Journal of Electrical and Computer Engineering (IJECE), vol. 3, no. 3, Jun. 2013. [Online]. Available: http://www.iaesjournal.com/online/index.php/IJECE/article/view/3474

[10] T. Benamimour, A. Bentounsi, and H. Djeghloud, "Study of Wind Turbine based Variable Reluctance Generator using Hybrid FEMM-MATLAB Modeling," International Journal of Electrical and Computer Engineering (IJECE), vol. 7, no. 1, pp. 1-11, 2017.

[11] K. V. Vidyanandan and N. Senroy, "Primary frequency regulation by deloaded wind turbines using variable droop," IEEE Transactions on Power Systems, vol. 28, no. 2, pp. 837-846, May 2013.

[12] M. Dreidy, H. Mokhlis, and S. Mekhilef, "Inertia response and frequency control techniques for renewable energy sources: A review," Renewable and Sustainable Energy Reviews, vol. 69, pp. 144 - 155, 2017.

[13] G. Ramtharan, J. Ekanayake, and N. Jenkins, "Frequency support from doubly fed induction generator wind turbines," IET Renewable Power Generation, vol. 1, no. 1, pp. 3-9, Mar. 2007.

[14] I. F. Moore, "Inertial Response from Wind Turbines," Ph.D. thesis, Cardiff University, Cardiff, 2012.

[15] H. Camblong, I. Vechiu, X. Guillaud, A. Etxeberria, and S. Kreckelbergh, "Wind turbine controller comparison on an island grid in terms of frequency control and mechanical stress," Renewable Energy, vol. 63, pp. 37-45, Mar. 2014.

[16] T. H. Mohamed, J. Morel, H. Bevrani, and T. Hiyama, "Model predictive based load frequency control_design concerning wind turbines," International Journal of Electrical Power \& Energy Systems, vol. 43, no. 1, pp. $859-867,2012$.

[17] S. Ruiz, J. Patiño, and J. Espinosa, "Load Frequency Control of a Multi-area Power System Incorporating Variable-speed Wind Turbines," in Conference Proceedings of XVII LATIN AMERICAN CONFERENCE IN AUTOMATIC CONTROL, Medellín, Colombia, 2016, pp. 447-452.

[18] A. Mullane and M. O'Malley, "The Inertial Response of Induction-Machine-Based Wind Turbines," Power Systems, IEEE Transactions on, vol. 20, no. 3, pp. 1496-1503, Aug. 2005.

[19] J. B. Ekanayake, N. Jenkins, and G. Strbac, "Frequency response from wind turbines," Wind Engineering, vol. 32, no. 6, pp. 573-586, 2008.

[20] G. Ramtharan, N. Jenkins, and O. Anaya-Lara, "Modelling and control of synchronous generators for wide-range variable-speed wind turbines," Wind Energy, vol. 10, no. 3, pp. 231-246, 2007. 
[21] G. Goodwin, S. Graebe, and M. Salgado, Control System Design. Prentice Hall, 2001.

\section{BIOGRAPHIES OF AUTHORS}
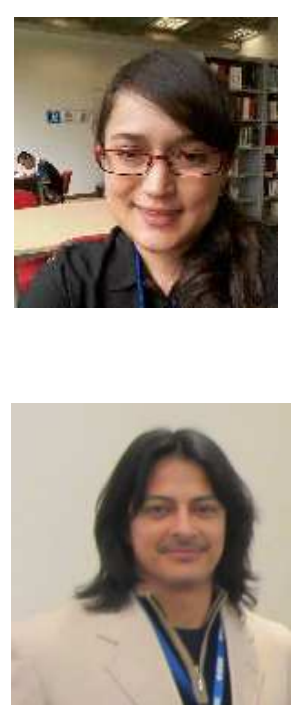

Julian Patiño was born in Medellín, Colombia. He received the B.S. degree in control engineering from Universidad Nacional de Colombia at Medellín, Colombia and the M.S. degree in Industrial Automation from the Universidad Nacional de Colombia at Manizales, Colombia, in 2008 and 2011, respectively. He is currently pursuing the Ph.D. degree in Automatics at the latter institution. His research interests include frequency control of power systems and renewable energy sources.

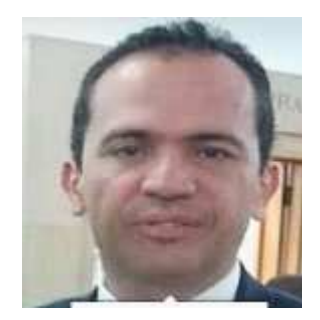

Jairo Espinosa (SM06) was born at Bogotá, Colombia. He received the Electronic Engineering degree from Universidad Distrital de Bogotá, and the masters (cum laude) and Ph.D. (magna cum laude) degrees in electrical engineering from the Katholieke Universiteit Leuven, Leuven, Belgium. He was the Research and Development Manager with IPCOS N.V., Leuven, researching on advanced process control systems, inferential sensors, and process optimization. He has experience in many industrial areas, including oil, polymers, automotive, power generation, and iron production. He is currently a Full Professor with the Universidad Nacional de Colombia at Medellín, Colombia. His current research include large-scale systems, intelligent control, mathematical modeling, model-based predictive control, signal processing, optimization, and model reduction techniques. 